\title{
Temperature Sensitivity of Mutants of Bacillus anthracis Caused by a Block in Thymine-Nucleotide Synthesis
}

\author{
By G. IVÁNOVICS \\ Institute of Microbiology, University Medical School, Szeged, Hungary
}

(Received 28 November 1963)

\section{SUMMARY}

Mutants were isolated from the non-capsulated strain Vollum of Bacillus anthracis which were unable to grow above $34^{\circ}$ in the absence of certain pyrimidines. At elevated temperatures, one of the mutants, VC-TdR-, was found to be dependent on thymidine while the other, $\mathrm{VC}^{-} \mathrm{T}^{-}$, required thymine. Both mutants, however; grew normally in the absence of pyrimidines at near to room temperature. A relatively high concentration of thymine was needed in order to overcome the thymidine requirement of mutant $\mathrm{VC}^{-} \mathrm{TdR}^{-}$at $37^{\circ}$, whereas a combination of a low concentration of thymine with different deoxyribosides (deoxyadenosine, deoxyguanosine, deoxycytidine) gave good growth of the mutant. This observation is suggestive of the presence of a particular enzyme, trans- $\boldsymbol{N}$-deoxyribosylase, in the mutant VC-TdR-, an enzyme which appears to be of limited distribution in nature. The second mutant, $\mathrm{VC}^{-} \mathrm{T}^{-}$, utilized added thymine readily at $37^{\circ}$ and the base could not be substituted by its nucleoside, thymidine. In fact, thymidine and deoxyribonucleosides inhibited the growth of mutant $\mathrm{VC}^{-} \mathrm{T}^{-}$in the presence of thymine.

Both mutants also grew well at $37^{\circ}$ in the presence of thymidine-5phosphate, which indicated that the de novo pathway of pyrimidine synthesis is blocked above $34^{\circ}$ somewhere in the pathway between deoxycytidine-phosphate and thymidine-5-phosphate. This block in the pyrimidine synthesis occurring at elevated temperatures caused an unbalanced synthesis of macromolecules accompanied by an abnormal cell-wall formation. At $37^{\circ}$, germinated spores showed an abnormal elongation of the initial cell concomitant with a gradual loss of viability. At this temperature cell-wall formation was also abnormal at limiting concentrations of pyrimidines and minor deficiencies in cell-wall structure of the mutants were still apparent even in the presence of a large excess of pyrimidine. This, however, did not involve any change in virulence of mutant $\mathrm{VC}+\mathrm{TdR}-$ in the homoiothermic mouse.

It is assumed that the mutants produce an altered enzyme protein corresponding to a block in de novo synthesis of pyrimidine, or that an inhibitor is produced at high temperatures which diminishes and finally prevents the action of the normal enzyme.

\section{INTRODUCTION}

A number of amino acids, salts, glucose and glutamine were defined by Gladstone (1939) as the minimal nutritional requirement of Bacillus anthracis. A certain proportion of each amino acid in the basal medium was found to be essential since inhibition of growth is caused by some of the amino acids in excess (Gladstone, 1939). The pure amino acid mixture was replaced later by casein hydrolysate, 
which was not only practicable, and by coincidence resembled the mixture giving optimal growth (Brewer et al. 1946). The growth of the bacteria in media consisting of amino acids, salts and glucose alone is poor but growth is very much stimulated by the addition of several growth factors. Thiamine was found to be the most potent stimulator but optimal growth was achieved only in the presence of further metabolites, primarily purine and pyrimidine bases (Brewer et al. 1946; Belton \& Strange, 1954; Puziss \& Wright, 1954; Thorne \& Belton, 1957).

Growth factors having a simple stimulatory effect on the growth of Bacillus anthracis cannot be considered as essential nutrients for this pathogen. In view of this fact, an attempt was made to isolate mutants with definite essential requirements, e.g. requirements which are not stimulatory but indispensable. In the course of such an investigation Ivánovics, Varga \& Marjai (1963) succeeded in isolating a few mutants, each with a clear essential requirement, e.g. for lactoflavin, uracil or purine bases. These mutants were found capable of growing only in the presence of the essential metabolite; therefore they could be considered as auxotrophs of $B$. anthracis.

In one experiment, after replication from yeast extract peptone medium to chemically defined casein hydrolysate agar medium, three individual colonies grew at room temperature but not at $37^{\circ}$. A detailed study of these isolates initially revealed a thymidine dependency of this mutant at $37^{\circ}$. As has been described recently (Ivánovics, 1963), unbalanced growth could be induced in this mutant by a temperature shift. During the course of these studies a secondary temperaturesensitive derivative appeared which was dependent on thymine instead of thymidine. Both mutants grew well in the presence of thymidine-5-phosphate. A detailed description of these mutants will be given in the present paper.

\section{METHODS}

Organisms. A non-capsulated mutant of Bacillus anthracis, strain Vollum, which was described earlier (Ivánovics, 1962) served as a parent for obtaining mutants. This strain will be referred to as $\mathrm{VC}-$ in this paper.

Chemicals. Commercial grades of analytical purity were employed for preparing defined media. Purine and pyrimidine bases were purchased from Fluka A.G. Chemische Fabrik (Basel); thymidine and thymidine-5-phosphate were products of Biochemical Corporation (Cleveland). The other deoxyribosides were kindly provided by Dr H. Amos (Harvard Medical School, Boston).

Basal casein hydrolysate medium (BCM). The double strength medium consists of: Casamino acids, vitamin-free (Difco), 10.0 g.; L-glutamic acid, 1.0 g.; DL-tryptophan and L-cystine, $0.05 \mathrm{~g}$; sodium citrate, $0.8 \mathrm{~g}$.; $\mathrm{K}_{2} \mathrm{HPO}_{4}, 4.0 \mathrm{~g}$.; $\mathrm{Na}_{2} \mathrm{SO}_{4}$, 0.02 g.; $\mathrm{MgSO}_{4} .7 \mathrm{H}_{2} \mathrm{O}, 0.02 \mathrm{~g}$.; ferric ammonium citrate, $10.0 \mathrm{mg}$.; $\mathrm{MnSO}_{4}, 4.0 \mathrm{mg}$.; distilled water $1 \mathrm{l}$. Each ingredient was dissolved separately and mixed in the given order. The $\mathrm{pH}$ of the medium was adjusted to $7 \cdot 2$ with $\mathrm{N}-\mathrm{NaOH}$, distributed in $200 \mathrm{ml}$. volumes, and sterilized at $110^{\circ}$ for 30 min. Double strength medium was diluted with the same volume of either sterile distilled water or $3 \%$ agar solution; $10 \mathrm{ml}$. of $20 \%$ glucose solution was added aseptically per litre of medium. Commercial agar was washed (several times) before use.

Complete casein hydrolysate medium (CCM). Double strength BCM was completed 
with thiamine, $p$-aminobenzoic acid, nicotinic acid amide, each at $1 \mu \mathrm{g} . / \mathrm{ml}$.; folic acid, pyridoxin, pyridoxal, pantothenic acid, each at $0.5 \mu \mathrm{g} . / \mathrm{ml} . ;$ lactoflavin, $0.25 \mu \mathrm{g} . / \mathrm{ml}$.; biotin, $0.01 \mu \mathrm{g} . / \mathrm{ml}$.; cyanocobalamine, $0.005 \mu \mathrm{g} . / \mathrm{ml}$.; guanine, adenine, hypoxanthine, thymine and uracil, each at $5 \mu \mathrm{g} . / \mathrm{ml}$.

When partially completed BCM medium was needed, individual metabolites were added to the basal medium. Pyrimidine base-free medium was made by omitting uracil and thymine from CCM.

Yeast extract peptone medium. YP broth or agar was prepared as described previously (Ivánovics \& Alföldi, 1955).

Method for determining nutritional requirement of mutants. The essential requirements of mutants at $37^{\circ}$ were examined either in liquid or on solid media. Assay of the essential metabolites in liquid medium was carried out as follows: various amounts of single or of mixtures of metabolites were measured into a series of $160 \times 16 \mathrm{~mm}$. test tubes. Thymine and thymidine were added to the tubes before sterilization while solutions of other nucleosides and thymidine-5-phosphate were sterilized separately by filtration through membrane filters (Membran filter, Göttingen, Gruppe 8). These metabolites were added to the sterile media aseptically before inoculation. The volume in each tube was made up to $2.5 \mathrm{ml}$. with distilled water, and then $3 \mathrm{ml}$. of double strength CCM (without pyrimidine bases) was added. Tubes were covered with aluminium foil and sterilized at $110^{\circ}$ for $30 \mathrm{~min}$. Inoculation of tubes was made with a dilute spore suspension containing about 50 colonyformers ( $0.5 \mathrm{ml}$. of a spore suspension prepared in $2.3 \%$ glucose was added to each tube).

The incubation of the cultures was carried out in a maximally sloped position at $37^{\circ}$, and the rate of growth estimated by the optical density at $600 \mathrm{~m} \mu$ of the cultures.

When the nutritional requirements of mutants were investigated on agar plates, metabolites to be tested were measured into Petri dishes, mixed with melted casein hydrolysate agar and the plates inoculated with about 50 viable spores.

Testing for capsule formation of bacteria. Bacterial streaks were made on yeast extract casein hydrolysate agar and incubated in an atmosphere containing $25 \%$ $\mathrm{CO}_{2}$ (Ivánovics, 1962).

Spore materials. Unless otherwise stated spores were always used for inoculation. Well-dispersed spore suspensions of each isolate investigated were prepared according to Ivánovics (1962). Spore suspensions in distilled water were stored at $4^{\circ}$, and diluted appropriately with distilled water before use.

\section{RESULTS}

Isolation of a temperature-sensitive mutant from strain $\mathrm{VC}^{-}$. The procedure described by Wachsman \& Mangolo (1962) for isolating auxotrophs from Bacillus megaterium, using 8-azaguanine as a mutagen and used by us with Bacillus anthracis (Ivánovics et al. 1963), was effective in isolating the thermosensitive mutants. Bacteria were irradiated with ultraviolet light, treated with 8-azaguanine, and the surviving organisms finally allowed to spore. These spores were plated on yeast extract peptone agar (YP agar), and after incubation at $37^{\circ}$ the colonies were replicated on to BCM agar. In one experiment involving 250 colonies, three failed 
to appear on the replica plates after $24 \mathrm{hr}$ incubation at $37^{\circ}$. However, the missing colonies did develop on keeping the plates at room temperature for $48 \mathrm{hr}$. These mutants were apparently not capable of forming colonies on minimal agar at $37^{\circ}$ but were able to do so at a lower temperature.

All three temperature-sensitive isolates appeared to be identical on first examination, so only one was subjected to a detailed study. All the subsequent experiments described in this paper were carried out with a stock spore preparation. This material was obtained by plating mutant spores on BCM agar, and incubating at $26^{\circ}$ for 6 days. The spore suspension was prepared from a pool of 30 colonies.

Analysis of spore material of the temperature-sensitive mutant. When samples of spore material were plated on YP agar and incubated either at $37^{\circ}$ or $26^{\circ}$ for $48 \mathrm{hr}$, an identical number of colony-formers was observed. The same number of colonyformers was also seen on BCM plates at $26^{\circ}$. In contrast, no colonies were formed when an inoculum giving rise to $10^{7}$ colonies at $26^{\circ}$ was distributed on $\mathrm{BCM}$ plates and incubated at $37^{\circ}$. Thus, among $10^{7}$ viable spores of temperature-sensitive mutant no back mutants were detected. On the other hand, about $1 / 10^{5}$ spores gave rise to colonies at $37^{\circ}$ when plated on CCM agar instead of BCM agar. The colonies which developed on CCM agar at $37^{\circ}$ reached a diameter of 4-6 mm. by $24 \mathrm{hr}$. These colonies did not grow when they were transferred to BCM agar and incubated at $37^{\circ}$. This showed that the spores of temperature-sensitive mutants consist of a population in which two distinct types of colony-formers are present. The growth requirement at $37^{\circ}$ of the majority type could be met by thymidine. This type will be referred to as $\mathrm{VC}-\mathrm{TdR}-$. The minority type, designated $\mathrm{VC}^{-} \mathrm{T}^{-}$, is characterized by its dependency on a low concentration of thymine at $37^{\circ}$. When a number of BCM plates were inoculated from individual colonies of VC-TdRand incubated at $26^{\circ}$ until sporulation was complete, the proportion of $\mathrm{VC}^{-} \mathrm{T}-$ spores varied from $10^{-5}$ to $10^{-7}$ in the cultures. It seems that $\mathrm{VC}^{-} \mathrm{T}^{-}$bacteria appeared in the cultures of $\mathrm{VC}^{-} \mathrm{TdR}^{-}$as secondary mutants of strain $\mathrm{VC}^{-}$. Table 1 illustrates the growth requirements at $37^{\circ}$ of the parent, strain $\mathrm{VC}^{-}$, and those of its derivatives.

Table 1. The growth of the parent strain, VC-, and of the mutants, VC-TdR- and $V C^{-} T^{-}$, on basal casein (BCM) agar supplemented with different metabolites, incubated at $37^{\circ}$ for $24 \mathrm{hr}$

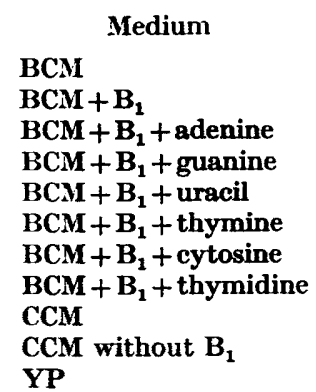

\begin{tabular}{|c|c|c|}
\hline \multicolumn{3}{|c|}{ The rate of growth } \\
\hline $\mathrm{VC}^{-}$ & VC-TdR- & $\mathbf{V C}-\mathbf{T}^{-}$ \\
\hline+ & - & - \\
\hline++ & - & - \\
\hline++ & - & - \\
\hline+++ & - & - \\
\hline++ & 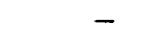 & - \\
\hline++ & - & +++ \\
\hline++ & - & - \\
\hline$+t$ & +++ & - \\
\hline+++ & & +++ \\
\hline+++ & ++++ & $+++t$ \\
\hline
\end{tabular}

Rate of growth: + , colonies $1 \mathrm{~mm}$. in diam. or smaller;,$++ 1-3 \mathrm{~mm} . ;+++\mathbf{3 - 7} \mathrm{mm}$.; $++++>7 \mathrm{~mm} . B_{1}=1 \mu \mathrm{g} . / \mathrm{ml}$. thiamine; the concentration of purine or pyrimidine bases was $5 \mu \mathrm{g} . / \mathrm{ml}$. each. 
It can be seen that the requirements of the mutants are highly specific. In addition, Table 1 demonstrates that thiamine appears to be an effective stimulatory nutrient for the parent, and for its mutant strains.

Standard CCM medium which contains as little as $2.5 \mu \mathrm{g}$. thymine/ml. and about $1 / 10^{5}$ of stock spore material gave rise to colonies (4-6 mm. in diameter) after $24 \mathrm{hr}$ at $37^{\circ}$, even at this low concentration of thymine. In fact, as a result of plating stock spore material at increasing concentration of thymine, the number of colony formers was found to be approximately proportional to the concentration of thymine. In the presence of $20 \mu \mathrm{g}$. thymine/ml. about $1 \%$ of viable spores gave rise to colonies; at $100 \mu \mathrm{g} . / \mathrm{ml} .30-40 \%$; and at $200 \mu \mathrm{g} . / \mathrm{ml}$. nearly $100 \%$ of spores formed colonies.

The growth of spores of VC-TdR- at a high concentration of thymine was slow and they were only $0.5-2 \mathrm{~mm}$. diam. after $24 \mathrm{hr}$ at $37^{\circ}$. Bacteria of strain VC-TdRgrown at a high concentration of thymine preserved their original characters. When their colonies were transposed to plates containing a low concentration of thymine, they did not grow. On the other hand, a good growth appeared on BCM agar containing as little as $2.5 \mu \mathrm{g}$. thymidine $/ \mathrm{ml}$.

Some cultural characteristics of the mutants. The effect of temperature on the growth of mutants and parent strains was studied in liquid BCM and CCM (Table 2).

Table 2. The growoth of the parent strain $V C^{-}$and its derivatives at different temperatures after incubation for $48 \mathrm{hr}$

\begin{tabular}{|c|c|c|c|c|}
\hline \multirow[b]{2}{*}{ Medium } & \multirow{2}{*}{$\begin{array}{c}\text { Temperature } \\
\left({ }^{\circ} \mathbf{C} .\right)\end{array}$} & \multicolumn{3}{|c|}{ Optical density values } \\
\hline & & vC- & VC-TdR- & $\mathbf{V C}-\mathbf{T}^{-}$ \\
\hline $\mathbf{B C M}$ & $\begin{array}{l}26 \cdot 0 \\
29 \cdot 0 \\
\mathbf{8 2} \cdot 2 \\
\mathbf{8 4} \cdot 2 \\
\mathbf{8 7} \cdot 0\end{array}$ & \begin{tabular}{l|l|}
$0 \cdot 40$ \\
$0 \cdot 34$ \\
$0 \cdot 81$ \\
$0 \cdot 12$ \\
0.07
\end{tabular} & $\begin{array}{l}0.25 \\
0.26 \\
0 \cdot 10 \\
0.00 \\
0.00\end{array}$ & $\begin{array}{l}0.80 \\
0.80 \\
0.09 \\
0.00 \\
0.00\end{array}$ \\
\hline $\mathbf{C C M}$ & $\begin{array}{l}26 \cdot 0 \\
29 \cdot 0 \\
32 \cdot 4 \\
84 \cdot 2 \\
87 \cdot 0\end{array}$ & $\begin{array}{r}0.78 \\
>0.76 \\
>0.65 \\
>0.66 \\
>0.78\end{array}$ & $\begin{array}{l}0.62 \\
0.64 \\
0.82 \\
0.00 \\
0.00\end{array}$ & $\begin{array}{l}0.65 \\
0.58 \\
0.50 \\
0.48 \\
0.82\end{array}$ \\
\hline
\end{tabular}

Values marked with $>$ were obtained in cultures where marked aggregation of the bacteria occurred despite energetic shaking before estimating their o.D.

The cultures were made as described under Methods and incubated in the sloped position.

With increased temperature the growth response of bacteria was considerably affected. The mutants did not grow at $34^{\circ}$ or above on BCM. In CCM the growth response of the parent strain was almost the same at all temperatures investigated. The growth of $\mathrm{VC}^{-} \mathrm{T}^{-}$at elevated temperatures was apparently due to the presence of thymine in CCM.

The spores of temperature-sensitive mutants gradually died when they were exposed to $87^{\circ}$ in BCM. The loss of viability of $\mathrm{VC}-\mathbf{T d R}-$ spores followed first order kinetics. Between 97.5 and $98.5 \%$ of spores lost their viability after $24 \mathrm{hr}$ incubation at $37^{\circ}$ (Fig. 1). A similar result was observed under identical conditions with spores of $\mathrm{VC}^{-} \mathrm{T}^{-}$. 
When suspensions of spores in distilled water were exposed to $40^{\circ}$ for $24 \mathrm{hr}$ no appreciable decrease in number was seen.

It could be concluded from theseobservations that the inoculum died during germination and not because the spores were extremely heat sensitive. This was confirmed by microscopical examination of an inoculum made at intervals during incubation at $37^{\circ}$. Samples were removed at intervals from heavily seeded BCM plates by touching the surface with coverslips and the preparations stained by Gutstein's (1926) method. A gradually increasing number of germinated spores was observed and after about $2 \mathrm{hr}$ all the spores appeared to have germinated. Germination was followed by an abnormal elongation of vegetative bacteria, six to eight times that seen in normal cultures of this pathogen. Very few intersepta were visible and the cell wall stained poorly (Pl. 1, fig. 1). After 4-6 hr, the organisms ceased to grow and a gradual disintegration of the bacteria ensued; by the next day most of the cells were broken and disintegrated. The same sequence of events could be observed when $3-4 \%(w / v)$ sucrose was incorporated into the medium.

In contrast, normal growth of temperature-sensitive mutants occurred even on minimal medium at $26^{\circ}$, this being demonstrable both by the colony form and by the morphological appearance of the bacteria. Cultures of mutants VC-TdRand $\mathrm{VC}^{-} \mathrm{T}^{-}$on $\mathrm{BCM}$ agar after $48 \mathrm{hr}$ incubation at $26^{\circ}$ appeared to be identical with those of the parent strain $\mathrm{VC}^{-}$. These opaque and convex colonies reached about 3-4 $\mathrm{mm}$. in diameter and contained characteristic anthrax organisms; long evenly segmented 'bamboo-like' threads with distinct parallel intersepta (Pl. 1, fig. 2).

The amounts of pyrimidines required by the temperature-sensitive mutants at $37^{\circ}$. Half-maximum growth was reached by mutant VC-TdR- in liquid defined media in the presence of approx. $0 \cdot 1 \mu \mathrm{g}$. thymidine/ml. (Fig. $2 b$ ). Strain $\mathrm{VC}^{-\mathrm{T}}{ }^{-}$exhibited a similar growth response to thymine but at a ten times higher concentration than that of VC-TdR- to thymidine (Fig. $2 a$ ). It was found that addition of pyrimidine bases had no significant effect on the growth response of strain $\mathrm{VC}^{-} \mathrm{TdR}^{-}$to thymidine.

Individual organisms of the mutant strains were found to be abnormal when they were cultivated at $37^{\circ}$ on either BCM or on CCM agar containing various concentrations of pyrimidines. At limiting concentrations of the pyrimidines, cell-wall formation was markedly affected. Mutant $\mathrm{VC}^{-} \mathbf{T d R}^{-}$, grown at $37^{\circ}$ in the presence of $0.5-1.0 \mu \mathrm{g}$. thymidine $/ \mathrm{ml}$., formed stunted colonies consisting of many bizarrely shaped bacteria. Thus, long filaments without intersepta, heavily distorted and disintegrated cells were seen in preparations stained for cell walls (Pl. 1, fig. 3). Gram staining also revealed extreme abnormalities in the cell structure (Pl. 1, fig. 4). By increasing the concentration of thymidine in CCM agar, malformation of the cell wall was diminished. Nevertheless, even at concentrations as high as 10-50 $\mu \mathrm{g}$ thymidine/ml., cell-wall formation was not completely normal. A few bacteria showed a poor cell-wall stain, but, in addition, the majority of filaments were not uniformly septated, in marked contrast to bacteria grown at $26^{\circ}(\mathrm{Pl}$. 1, figs. 5, 6).

Similar observations were made when the thymine-dependent mutant, $\mathrm{VC}^{-} \mathbf{T}^{-}$, was grown at $37^{\circ}$ in the presence of different concentrations of this base. Severe deficiencies in the cell wall were apparent at concentrations of 1-3 $\mu \mathrm{g}$. thymine $/ \mathrm{ml}$. and minor abnormalities in the cell-wall formation were still to be seen at $200 \mu \mathrm{g}$. thymine/ml. 


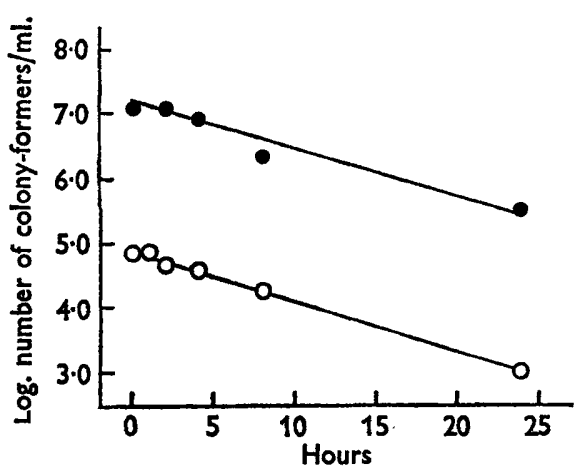

Fig. 1

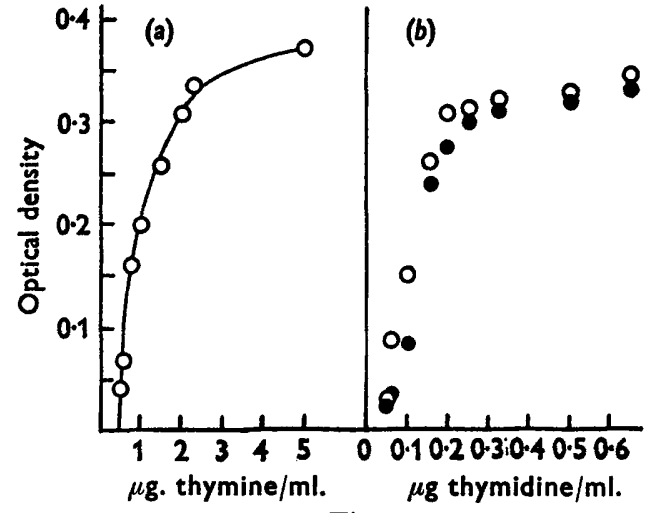

Fig. 2

Fig. 1. The decrease in the number of colony-formers of VC-TdR-spores after incubation . at $37^{\circ}$ in basal medium. Samples of spore material were plated on BCM agar, and incubated at $37^{\circ}$. Plates were taken at intervals and reincubated for $48 \mathrm{hr}$ at $26^{\circ}$. The number of colony-formers given in the figure is directly related to the total number of colony-formers in the original spore material. $\mathrm{O} 100 \mathrm{ml}$. of liquid $\mathrm{BCM}$ was inoculated with $0.05 \mathrm{ml}$. of spore material and incubated at $37^{\circ}$. Samples were taken at intervals, and plated on YP agar. The plates were incubated at $37^{\circ}$ for $24 \mathrm{hr}$, and scored for colonyformers.

Fig. 2. The growth response of strains VC-TdR- and VC-T- to thymidine and thymine respectively. CCM without pyrimidine base was used as medium. Incubated at $37^{\circ}$ for $24 \mathrm{hr}$.

(a) Strain VC-T-; (b) strain VC-TdR-. O, In the presence of $10 \mu \mathrm{g} . / \mathrm{ml}$. uracil and thymine; 9 , without these bases.

The microscopic examination of cells of the temperature-sensitive mutants revealed that cell-wall formation at $37^{\circ}$ was slightly abnormal even when an excess of the pyrimidine was added. The minor abnormalities in cell-wall formation therefore cannot be considered as a direct consequence of pyrimidine depletion alone.

Analysis of the block in the pyrimidine synthesis of the mutants. The results of observations with both mutants, $\mathrm{VC}-\mathrm{TdR}^{-}$and $\mathrm{VC}-\mathrm{T}^{-}$, can be dealt with briefly as follows:

(1) Thymidine-5-phosphate (TdRP) supported the growth of both mutants at $37^{\circ}$. The minimal concentration of TdRP supporting full growth of VC-TdR- and VC-T- bacteria was about $5 \mu \mathrm{g} . / \mathrm{ml}$. at $37^{\circ}$. This requirement of strain VC-TdRappeared to be about ten times greater than that for thymidine. It should be stressed again that thymidine in contrast to TdRP did not support the growth of VC-T-.

When spores of both mutants were plated on pyrimidine-free CCM agar containing $5 \mu \mathrm{g}$. TdRP/ml., all viable spores formed colonies, indicating an identical response of individual spores to this nucleotide.

(2) The thymidine requirement of strain $\mathrm{VC}-\mathrm{TdR}-$ at $37^{\circ}$ could not be replaced by other deoxyribosides. In the absence of thymine in medium CCM, no growth was observed in the presence of $20 \mu \mathrm{g} . / \mathrm{ml}$. of deoxyadenosine (AdR), deoxycytidine (CdR), or deoxyguanosine (GdR). On the other hand, good growth occurred in media containing a low concentration of thymine when the deoxyribosides were added (Table 3). 
Table 3. The growth of mutant VC-TdR-as measured by final optical density in the presence of thymine and of individual deoxyribosides

\begin{tabular}{|c|c|c|c|c|c|c|c|c|c|}
\hline \multirow{3}{*}{$\begin{array}{l}\text { Thymine } \\
\text { ( } \mu \mathrm{g} . / \mathrm{ml} .)\end{array}$} & \multicolumn{9}{|c|}{ Additional substances $(\mu \mathrm{g} . / \mathrm{ml})}$. \\
\hline & \multirow[b]{2}{*}{ None } & \multirow{2}{*}{$\begin{array}{c}\text { TdR } \\
5\end{array}$} & \multicolumn{2}{|c|}{ AdR } & \multicolumn{2}{|c|}{ CdR } & \multicolumn{2}{|c|}{ GdR } & \multirow{2}{*}{$\begin{array}{r}\text { d } \\
40\end{array}$} \\
\hline & & & 20 & 40 & 20 & 40 & 20 & 40 & \\
\hline $\mathbf{0}$ & 0.00 & $0 \cdot 28$ & $0 \cdot 00$ & $0 \cdot 00$ & 0.00 & 0.00 & 0.00 & $0 \cdot 00$ & 0.00 \\
\hline 5 & 0.00 & - & 0.23 & $0 \cdot 26$ & 0.06 & 0.06 & 0.06 & 0.23 & 0.00 \\
\hline 10 & 0.00 & - & 0.83 & 0.28 & 0.23 & 0.25 & $0 \cdot 18$ & 0.23 & 0.00 \\
\hline
\end{tabular}

Different amounts of thymine and various deoxyribosides were added to CCM without pyrimidines and the tubes were inoculated with 30 spores of the mutant, VC-TdR-. Incubated at $37^{\circ}$ for $24 \mathrm{hr}$. Abbreviations (see text): TdR, thymidine; d, deoxyribose.

Thymine at a low concentration, while not supporting growth alone, did so in combination with any of the deoxyribosides. The rate of growth was found to be dependent on the concentration of both thymine and the deoxyribosides. According to the individual deoxyriboside used there was some variation in the rate of growth, the most effective being AdR. The pentose, deoxyribose itself, was found to be ineffective in supplementing thymine.

Similar observations were found when combinations of thymine and deoxyribosides in solid medium were investigated. On CCM agar plates containing $10 \mu \mathrm{g}$. thymine $/ \mathrm{ml}$. and $20 \mu \mathrm{g}$. AdR/ml. all viable spores inoculated gave rise to welldeveloped colonies (3 $\mathrm{mm}$. diam.). Only a proportion of spores developed when AdR was substituted either with CdR or with GdR. Thus, only half the viable spores formed colonies in the presence of CdR plus thymine after $24 \mathrm{hr}$ at $37^{\circ}$, and only $20-30 \%$ in the presence of GdR plus $10 \mu \mathrm{g}$. thymine $/ \mathrm{ml}$.

These observations indicated some heterogeneity in the spore population as to their ability to utilize thymine in the presence of deoxyribosides. The variation appears, however, to be more quantitative than qualitative. By increasing the concentration of either thymine or deoxyriboside, or by extending the incubation period, the percentage of colony-formers can reach 100 .

When thymine was replaced by $2 \mu \mathrm{g}$. thymidine/ml. in CCM, the growth of VC-TdR ${ }^{-}$was neither inhibited nor enhanced by addition of the other deoxyribosides.

(3) The thymine-requiring mutant, $\mathrm{VC}^{-} \mathrm{T}^{-}$, did not grow in the absence of this base at $37^{\circ}$, but the nucleotide could replace thymine while the nucleoside, thymidine, was ineffective. Moreover, thymidine actually prevented growth at $37^{\circ}$ in the presence of thymine. This antagonism appeared to be competitive. When increasing amounts of thymidine were added to a series of tubes containing CCM plus $400,200,100$ and $50 \mu \mathrm{g}$. thymine $/ \mathrm{ml}$. and inoculated with $\mathrm{VC}-\mathrm{T}^{-}$spores, the growth of bacteria was proportional to the ratio of base and nucleoside (Fig. 3).

According to the concentration of thymine used, 1 mole of thymidine successfully prevented the $50 \%$ utilization of $391,399,305$ and 260 mole of thymine.

This inhibition of thymine utilization by strain $\mathrm{VC}^{-} \mathrm{T}^{-}$was not restricted to thymidine, since all deoxyribonucleosides showed a similar effect. Nucleosides AdR, CdR and GdR at a concentration of $1.5 \mu \mathrm{g} . / \mathrm{ml}$. gave a $50 \%$ inhibition in the 
presence of $50 \mu \mathrm{g}$. thymine $/ \mathrm{ml}$., and $2 \mu \mathrm{g}$. nucleosides $/ \mathrm{ml}$. completely suppressed the growth of bacteria. No inhibition of growth was, however, observed when deoxyribose instead of deoxyribosides was added to the system.

The pathogenicity of mutant $V C-T d R-$. Neither the non-capsulated parent strain VC- nor its mutant VC-TdR- killed mice in a dose of a million organisms but two out of five mice were killed by about $10^{8}$ organisms of mutant VC-TdR- injected intraperitoneally; the bacteria recovered formed mucoid colonies in the presence of $25 \% \mathrm{CO}_{2}$. This mucoid growth was allowed to sporulate, and samples of the spore material were plated on BCM, CCM and YP agar and incubated at $37^{\circ}$.

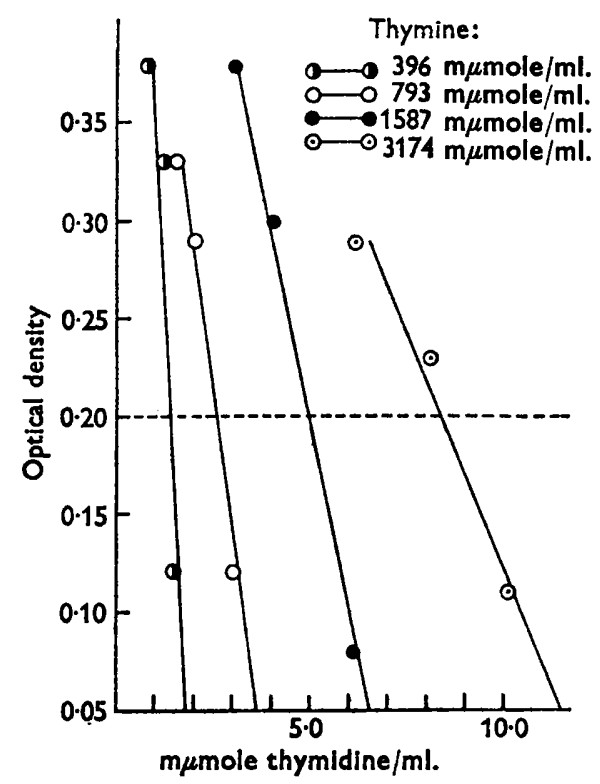

Fig. 3. About $50 \%$ inhibition of growth (0.2 optical density values) of strain VC-Tby thymidine at different concentrations of thymine.

Table 4. The virulence of mutant $V C+T d R$ - for mice

$\begin{array}{cc}\begin{array}{c}\text { No. of spores } \\ \text { inoculated } \\ \text { subcutaneously }\end{array} & \begin{array}{c}\text { Mice dying } \\ \text { (dead/total) }\end{array} \\ 5 \times 10 & 2 / 3 \\ 5 \times 10^{2} & 2 / 3 \\ 5 \times 10^{3} & 8 / 3 \\ 5 \times 10^{4} & 8 / 8\end{array}$

The number of colonies formed differed considerably; about $1 / 10^{5}$ grew on BCM agar; these were revertants to the prototrophic type; about $1 \%$ of the spores grew on CCM agar; these were found to be thymine-dependent at $37^{\circ}$. These observations show that there was a mutation to thymine dependency and also a reversion to prototrophy during growth in the animal body. It appears that a series of independent mutations took place in the animal infected with spores of $\mathrm{VC}-\mathrm{TdR}-$. The sequence of mutations appeared to be: $\mathrm{VC}^{-} \mathrm{TdR}^{-} \rightarrow \mathrm{VC}+\mathrm{TdR}^{-} \rightarrow \mathrm{VC}+\mathrm{T}^{-} \rightarrow$ $\mathrm{VC}^{+}$; the latter being the wild-type strain Vollum. 
Groups of mice were then infected subcutaneously with increasing doses of mutant VC-TdR-. The result is shown in Table 4. It can be seen that a small number of spores was enough to kill mice. The virulence of the mutant VC+TdRdoes not differ significantly from that of wild-type strain Vollum (Ivánovics, 1962). Blood from these mice was also plated on YP agar and the bacteria which grew out were checked for capsule production and for additional requirements at $37^{\circ}$. A proportion (about $10^{-3}$ ) of colony-formers was found to be the thyminedependent, $\mathbf{V C}+\mathbf{T}^{-}$mutant.

This experiment showed that the strain $\mathrm{VC}^{+} \mathbf{T d R}-$ while dependent on thymidine at $37^{\circ}$ was capable of multiplying in the body of the homoiothermic mouse.

\section{DISCUSSION}

Although this study may not reflect the fine details of the minimal nutritional requirements of the prototrophic strain $\mathrm{VC}-$ at $26^{\circ}$ and $37^{\circ}$, it nevertheless appears that this strain of Bacillus anthracis has a somewhat more complex requirement at $37^{\circ}$ than at a lower temperature. In this respect $B$. anthracis appears to be similar to Pasteurella pestis, a pathogen having a definitely higher nutritional requirement at $37^{\circ}$ than below $32^{\circ}$ (Hills \& Spurr, 1952). It has been found (Ivánovics, Varga \& Marjai, to be published) that the adverse effect of incubation at $37^{\circ}$ on $B$. anthracis, strain $\mathrm{VC}^{-}$, was very much diminished by the presence of thiamine. On addition of adenine and guanine as well as thiamine, the difference in the rate of growth at $26^{\circ}$ and $37^{\circ}$ was only small. These facts suggest that the 'stimulatory' effect of some metabolites on the growth of $B$. anthracis may be explained by assuming that a 'salvage' pathway is put into operation in the presence of exogenous metabolites. Thus, the inhibition of the de novo pathway caused by elevated temperature is circumvented by addition of the appropriate metabolite.

The striking feature of the mutants described in this paper was their dependency on thymidine or thymine at a temperature above $34^{\circ}$. By decreasing the temperature of incubation, their dependency on pyrimidines could be diminished proportionally.

The primary mutant, $\mathrm{VC}^{-} \mathrm{TdR}^{-}$, had a requirement for thymidine at $37^{\circ}$; thymine can replace thymidine only at an unusually high concentration, as this base was utilized poorly and slowly. The secondary mutant, $\mathrm{VC}^{-} \mathbf{T}^{-}$, derived from the spore material of $\mathrm{VC}-\mathbf{T d R}-$ by selection at a low concentration of thymine exhibits a marked specificity to this base. Thymine could not be replaced by its nucleoside, thymidine. Nevertheless, both mutants grew similarly and well at $37^{\circ}$ on addition of thymidine-5-phosphate. This observation is rather striking, for the direct utilization of nucleotides by Enterobacteriaceae has long been open to question. On the other hand, experimental evidence indicates that Lactobacillus bulgaricus directly incorporates uracil-nucleotides (Rose \& Carter, 1954). There seems to be, therefore, a difference in the incorporation of nucleotides by different bacteria.

It appears that the de novo pathway of pyrimidine synthesis is blocked at nucleotide level somewhere in the pathway between thymidine-5-phosphate and deoxycytidine-phosphate. In trying to guess the position of this block in the mutants, other de novo pathways beside that represented by Scheme 1 should be considered. It is known (Cohen \& Barner, 1957) that Escherichia coli is capable of converting 
5-methyl-deoxycytidine to thymidine. Therefore, the position of the block represented by Scheme 1 has been arbitrarily chosen.

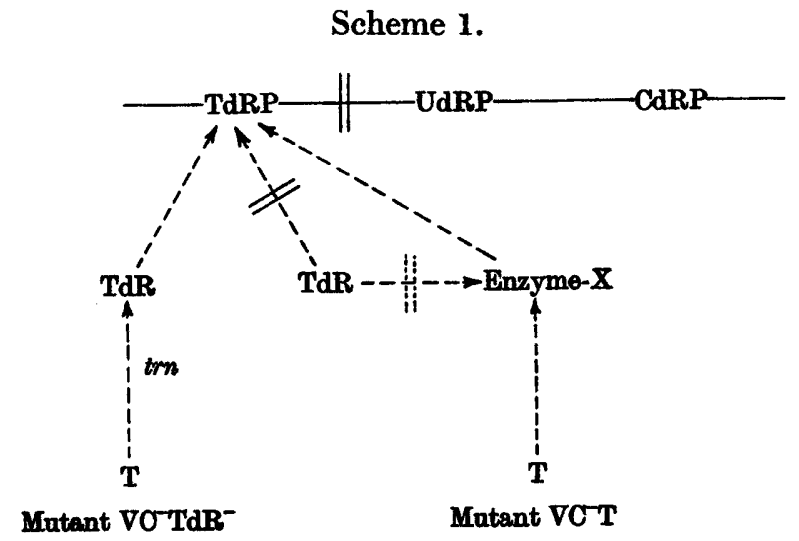

Key : CdRP, Deoxycytidine-phosphate; UdRP, deoxyuridine-phosphate; TdRP, thymidine-5phosphate; $\mathrm{T}$, thymine; TdR, thymidine; trn, trans-N-ribosylase; $=$, block in the conversion; $=$, enzyme inhibition but block in the TdR conversion; - - , de novo; - - , salvage pathway.

Mutant VC-TdR- utilized thymidine readily and the main salvage pathway in this mutant at elevated temperature therefore appeared to be the conversion of thymidine to its corresponding nucleotide.

It is safe to assume that in the utilization of thymine in mutant VC-TdR- the enzyme, trans- $\boldsymbol{N}$-deoxyribosylase, is involved. This enzyme has been described in Lactobacillus helveticus and $L$. delbrückii by MacNutt (1952), and renamed by Roush $\&$ Betz (1958). The enzyme is able to catalyse the transfer of the deoxyribosyl group in deoxynucleosides to purine or pyrimidine bases. The role of this enzyme is therefore concerned in the utilization of deoxyribonucleosides (McNutt, 1952). It was found that the spores of mutant $\mathrm{VC}^{-} \mathbf{T d R}^{-}$were capable of forming colonies at a high concentration of thymine, although the clones derived from individual spores varied in their ability to utilize this base. In fact, the utilization of thymine was poor and slow. Nevertheless, when a deoxyriboside (deoxyadenosine, deoxyguanosine, deoxycytidine) was added to the culture of mutant $\mathrm{VC}^{-} \mathrm{TdR}^{-}$, even a low concentration of thymine permitted growth. A combination of deoxyriboside and thymine was effective in supporting growth while deoxyriboside or thymine alone was ineffective.

It should be stressed, however, that mutant $\mathbf{V C}-\mathbf{T d R}-$ was able to grow, albeit poorly, in the absence of added deoxyribonucleoside, when a high concentration of thymine was present in the medium. The utilization of thymine in this case can probably be explained by a combination of purine-deoxyribosides supplied from the pool.

Mutant VC-T- was not capable of utilizing thymidine, although both the base and the nucleotide permitted growth at elevated temperature. Moreover, thymidine not only failed to support growth, but its presence competitively inhibited the utilization of thymine. This effect was not limited to thymidine but was brought about als $\mathrm{J}$ by the other deoxyribosides tested. It could be inferred from these 
observations that an enzyme (designated as enzyme-X in the Scheme) which incorporates thymine in the salvage pathway in this mutant has binding sites for both base and deoxyribosides. The failure to utilize thymidine may be due to absence of an adequate kinase in this mutant. Since thymine could not be utilized via nucleosides, it should be supposed that thymine reaches the main pathway in the mutant $\mathrm{VC}-\mathrm{T}$ - bypassing the nucleoside level and the base is thus converted directly to nucleotide. If this be the case, the existence of an enzyme (similar to the known phosphoribosyl pyrophosphorylases) should be considered which is capable of attaching to the base a deoxyribose-5-phosphate moiety.

The pyrimidine dependency of mutants at $37^{\circ}$ was associated with a malformation of cell wall. This was very pronounced at low concentrations of the pyrimidine. Restoration of cell-wall synthesis appeared to require a higher concentration of pyrimidine than that which was necessary to support the growth of the temperaturesensitive mutants. The morphological integrity of the cell wall was not totally restored even at a high excess of pyrimidines, suggesting that mutant growth at $37^{\circ}$ was not perfectly balanced during the incorporation of pyrimidines on the salvage pathway. Nevertheless, the capsulated mutant of thymidine-dependent bacteria was found to be fully virulent in mice.

It has been shown recently (Ivánovics, 1963) that an unbalanced synthesis of the essential macromolecules can be elicited by a temperature shift to $37^{\circ}$ in a culture of mutant $\mathrm{VC}-\mathrm{TdR}^{-}$growing exponentially without thymidine at room temperature. This unbalanced growth of Bacillus anthracis mutants is similar to several systems already known in Escherichia coli, where the lack of thymine (Barner \& Cohen, 1954) or the prevention of thymine synthesis (Cohen \& Barner, 1956; Tomasz \& Borek, 1962) causes unbalanced growth, followed by death, of bacteria. Thymine deprivation in the mutants of $B$. anthracis did not cause rapid death of the bacteria but rather a prolonged, gradual loss of viability.

Since normal growth of the temperature-sensitive mutants occurred at a low temperature, even in the absence of pyrimidines, it is obvious that the genes controlling the enzymes involved in the biosynthesis of thymine were functioning normally under these conditions. The block in the pyrimidine pathway at elevated temperature could be due to a mutation affecting a structural gene. Several mutants of micro-organisms have already been described where the mutation resulted in a synthesis of an altered but functional enzyme. Maas \& Davis (1952) described a mutant of Escherichia coli which required pantothenate for growth above $30^{\circ}$. The enzyme that catalysed pantothenate synthesis was found to be much more heatlabile than that in the corresponding preparation of the wild type. Fincham (1959) reviewed the data concerning qualitative alteration of enzymes caused by mutation in micro-organisms. In a recent study, Yanofsky, Helinski \& Maling (1961) described mutational changes of the $A$ gene controlling tryptophan synthetase in $E$. coli which lead to the formation of altered proteins differing in their solubility and heat stability. Nevertheless, quantitative enzymatic activity measurements failed to reveal differences between the mutants. It might therefore be assumed that the block in pyrimidine synthesis which manifests itself only at an elevated temperature in Bacillus anthracis mutants derives from a mutation in a structural gene. If this is the case, a production of an excessively heat-sensitive enzyme should be considered in the pyrimidine pathway. 
An alternative explanation of the thermosensitivity of mutants could be related to the production of an inhibitory substance at elevated temperature. It seems likely that in this case a gene of regulation is involved in the mutation. Unfortunately, no tool is yet available for the genetic analysis of Bacillus anthracis, so that this question cannot be answered at present.

I should like to thank Professor E. Borek and Dr A. Thomasz (Department of Biochemistry, Columbia University, New York) for reading the manuscript and for their valuable suggestions. I am also indebted to Dr B. Holland (Department of Biochemistry, University of Oxford) for his editorial help, and to Dr H. Amos (Department of Bacteriology, Harvard Medical School, Boston) for the deoxyriboside samples kindly sent to me.

\section{REFERENCES}

BARNer, H. D. \& CoHEN, S. S. (1954). The induction of thymine synthesis by $T_{2}$ infection of a thymine requiring mutant of Escherichia coli. J. Bact. 68, 80.

Belton, F. C. \& Strange, R. E. (1954). Studies on a protective antigen produced in vitro from Bacillus anthracis: medium and methods of production. Brit. J. exp. Path. 35, 144.

Brewer, C. R., McCullough, W. G., Mills, R. C., Roessler, W. G., Herbst, E. J. \& Howe, A. F. (1946). Studies on the nutritional requirement of Bacillus anthracis. Arch. Biochem. 10, 65.

Cohen, S. S. \& Barner, H. D. (1956). Studies on the induction of thymine deficiency and on the effect of thymine and thymidine analogues in Escherichia coli. J. Bact. 71, 588.

Cohen, S. S. \& Barnar, H. D. (1957). The conversion of 5-methyl-deoxycytidine to thymidine in vitro and in vivo. J. biol. Chem. 226, 631 .

Fincham, J. R. S. (1959). The biochemistry of genetic factors. Annu. Rev. Biochem. 28, 343.

GLadstone, G. P. (1939). Inter-relationship between amino acids in the nutrition of Bacillus anthracis. Brit. J. exp. Path. 20, 189.

Gutstein, M. (1926). Das Ektoplasm der Bakterien. Zbl. Bakt. (Abt. 1 Orig.), $100,1$.

Hius, G. M. \& SpUnR, E. D. (1952). The effect of temperature on the nutritional requirement of Pasteurella pestis. J. gen. Microbiol. 6, 64.

IváNovics, G. (1962). The pathogenicity of Bacillus anthracis lysogenic with mutants of phage W. J. gen. Microbiol. 28, 87.

IváNovics, G. (1963). Unbalanced growth induced by temperature shift in a mutant of Bacillus anthracis. Biochem. biophys. Res. Comm. 11, 343.

IVÁNovics, G. \& ALFöLdr, L. (1955). Observation on lysogenesis in Bacillus megaterium and on the megacin, the antibacterial principle of this Bacillus species. Acta microbiol. Acad. Sci. Rung. 2, 257.

Ivánovics, G., Varga, I. \& MarJat, E. (1963). Die Isolierung auxotropher Mutanten des Bacillus anthracis. Naturwissenschaften, 50, 674.

MaAs, W. K. \& Davis, B. D. (1952). Production of an altered pantothenate synthetizing enzyme by a temperature-sensitive mutant of Escherichia coli. Proc. nat. Acad. Sci., Wash. 38, 785.

MacNuTr, W. (1952). Enzymically catalyzed transfer of the deoxyribosyl group from one purine or pyrimidine to another. Biochem. J. 50, 884.

Puziss, M. \& Wright, G. G. (1954). Studies on immunity in anthrax. IV. Factor influencing elaboration of the protective antigen of Bacillus anthracis in chemically defined media. J. Bact. 68, 474.

Rose, J. A. \& Carter, C. F. (1954). Pyrimidine precursors for Lactobacillus bulgaricus. J. biol. Chem. 207, 701. 
Roush, A. H. \& Betz, R. R. (1958). Purification and properties of trans- $\boldsymbol{N}$-deoxyribosylase. J. biol. Chem. 233, 261.

Tronne, S. B. \& Belton, F. C. (1957). An agar-diffusion method for titrating Bacillus anthracis immunizing antigen and its application to study of antigen production. J. gen. Microbiol. 17, 505.

Thomasz, A. \& Borek, E. (1962). The mechanism of an osmotic instability induced in E. coli K-12 by 5-fluorouracil. Biochemistry, 1, 543.

Wachsman, J. T. \& Mangolo, R. (1962). Use of 8-azaguanin for the isolation of auxotrophic mutants of Bacillus megaterium. J. Bact. 83, 35.

Yanofsky, C., Helinski, D. R. \& Maling, B. D. (1961). The effects of mutation on the composition and properties of the A protein of Escherichia coli tryptophan synthetase. Cold Spr. Harb. Symp. quant. Biol. 26, 11.

\section{EXPLANATION OF PLATE}

Photomicrographs of strain VC-TdR- grown under different conditions. Cell-wall staining unless otherwise stated. Magnification $\times 1230$.

Fig. 1. Bacteria germinated from VC-TdR- spores on BCM agar after $4 \mathbf{h r}$ incubation at $37^{\circ}$.

Fig. 2. 'Bamboo-like' threads of VC-TdR- bacteria grown (in the absence of thymidine) on BCM agar. Incubated at $26^{\circ}$ for $48 \mathrm{hr}$.

Figs. 3-6. VC-TdR- bacteria grown on pyrimidine base-free CCM agar on addition of thymidine at various concentrations. Incubated at $37^{\circ}$ for $24 \mathrm{hr}$.

Fig. 8. In the presence of $0.5 \mu \mathrm{g}$. thymidine $/ \mathrm{ml}$.

Fig. 4. In the presence of 0.5 $\mu \mathrm{g}$. thymidine/ml. With Gram staining.

Fig. 5. In the presence of $10 \mu \mathrm{g}$. thymidine/ml.

Fig. 6. In the presence of $50 \mu \mathrm{g}$. thymidine $/ \mathrm{ml}$. 

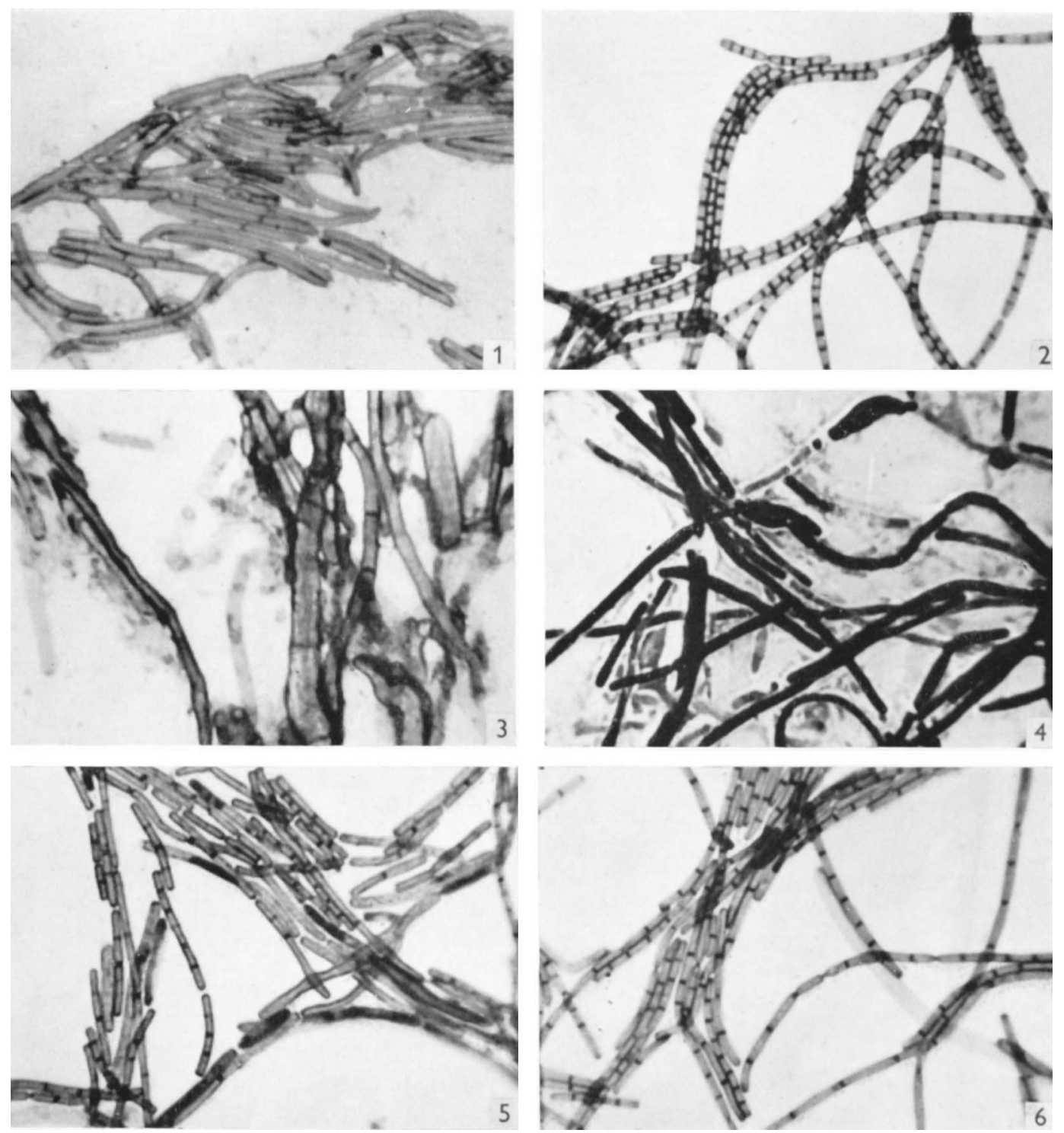